\title{
Estimation Cost Method Using Cost Significant Model On Channel Work in The Public Work In Sidoarjo
}

\author{
W Oetomo ${ }^{1}$, J Rochyantine ${ }^{2}$, K Koespiadi ${ }^{3}$, H T Tjendani ${ }^{4}$ \\ $\left\{\right.$ abarokaboel@yahoo.com $\left.{ }^{1}\right\}$ \\ 1,2,3,4Universitas 17 Agustus 1945 Surabaya, Indonesia
}

\begin{abstract}
The calculation of cost estimation that has been done so far in the Office of Public Works and Spatial Planning of Sidoarjo Regency was made based on experience in similar projects in previous years without any specific method, so that can not be identified any work that significantly affects the total cost the project. So that required an estimation method that is considered quite accurate and significantly affect the cost of the project, namely Cost Significant Model. This study aims to determine the components of work that significantly influence the total cost of channel development in Sidoarjo and calculate the estimated cost model of channel development with the method of "Cost Significant Model". The result of data analysis is known that cost significant item is the sum of percentage of work cost $\geq 80 \%$ of total cost of work that is stone masonry work, concrete, reinforcement, pile, and stone pitching. The most influential/significant work to the planning of development project per $\mathrm{m}$ channel work is stone masonry work, then sequentially are pile work, reinforcement work, and concrete work. The estimated model produced is $\mathrm{Y}=71.864,499+1,257 \mathrm{X} 1+1,235 \mathrm{X} 3+0,990 \mathrm{X} 4+$ $1,605 \mathrm{X} 5$, where $\mathrm{X} 1$ is stone masonry work, $\mathrm{X} 3$ is concrete work, $\mathrm{X} 4$ is reinforcement work, and X5is pile work. With the accuracy of cost estimation of the significant cost of the model between $-18,7.0 \%$ up to $+10.5 \%$, with an average accuracy of $0.2 \%$ and the value of Cost Model Factor (CMF) of 1.0000 then the estimated model obtained very well.
\end{abstract}

Keywords: channel, cost significant model, cost

\section{Introduction}

Protection of river restoration sections through structuring riverbed, river border arrangement, and river channel rehabilitation. Protection of river borders, in this case, is also very influential in the interests of flood control.

River development is realized in the form of river utilization, in Indonesia, in general, it is used for agriculture, environmental sanitation, industry, tourism, sports, defense, fisheries, power generation, and transportation.

Control of the destructive power of river water is carried out through flood risk management, which is intended to reduce the risk of magnitude and vulnerability of flooding. One effort can 
be made by building flood control infrastructure in the form of increasing river capacity and increasing embankments.

Cost Significant Model is one of the estimation techniques, which is a fundamental process in the construction of a physical facility because how much the cost to be used must be answered by an estimator as a system. With the existence of etymation, the owner (OPD) and other decision-makers in the construction project, can find out the amount of costs that will be budgeted for a project. It is clear, that the ability to estimate the initial costs is good (accurate) is the key to being able to step at the next stage of the project.

According to Mulyono and Apriyono [1] in the early stages of development, the information available regarding physical facilities is still very limited, so the estimated cost at this initial stage has a low level of accuracy. However, estimation of costs must be carried out for very strategic decision making, for example in a feasibility study, budgeting, and optimal design selection, considering that decision making in the initial stages will be very influential at a later stage. In order to make cost estimates better, at this early stage the information source factors, data accuracy, and estimation methods play a role in increasing this accuracy.

The Cost Significant Model method that will be developed in this research is expected to provide an answer to the demand for the availability of an initial cost estimate for the development of rehabilitation and channel improvement projects, especially those in the Sidoarjo Regency.

The research objectives to be achieved in this study are:

1. Knowing the components of work that have a significant effect on the total cost of building a channel in Sidoarjo.

2. Knowing and calculating the estimated cost of building a channel with the "Cost Significant Model" method on a channel development project within the Public Works and Spatial Planning Office of Sidoarjo Regency.

Knowing the accuracy of the estimated cost of channel construction in Sidoarjo with the "Cost Significant Model" method for factual costs.

This research is expected to be able to provide a positive contribution that is beneficial to some parties, among others, it is expected that the results of this study can be useful and useful for the Department of Public Works and Spatial Planning of Sidoarjo Regency. accounted for. In addition, the results of this study can be useful and useful for consultants and contractors, to calculate the estimated cost of building a channel quickly and accountably.

\section{Theoretical Review}

\subsection{Channel}

Classification of open channels based on the consistency of basic cross-section and slope forms, namely:

a. Prismatic channel

Namely the channels which form the basic cross-section and the basic slope, for example drainage channels and irrigation channels.

b. Non-prismatic channel

Namely, the channel which forms a cross-section and its basic slope changes, for example is a river. 


\subsection{Overview of Project Cost Estimates}

Costs required for a project can reach a very large number and be embedded in a long period of time. Therefore according to Husen [2], it is necessary to identify project costs.

Some cost estimation methods according to Suharto[3] are:

1. Parameter Method

2. Method of List of Price Indexes

3. Elemental Cost Analysis Method

4. Factor Method

5. Method of Quantity Take-Off

6. Unit Price Method

7. Project Data and Information Methods

\subsection{Barriers to Practice Cost Estimates}

The limited-time involved in estimating costs will cause obstacles in the estimation. According to Hajek [4], obstacles that may arise in the implementation of estimates, namely:

1. There are things that are missed

2. Inadequate details of work

3. Misinterpretation of function or project data.

4. Use of the wrong assessment technique

5. Failure to identify the main cost element.

\subsection{Percentage of Building Cost Components}

In construction project work the total project cost is the number of cost components which include: costs for labor, material costs, equipment costs, indirect costs, and profits.

\subsection{Cost Significant Model}

According to Poh and Horner [5] in the journal "Cost-significant modeling-potential for use in south-east Asia", the Cost Significant model is one of the construction cost forecasting models based on previous project information \& data, which relies more on the most significant price in influencing the total cost of the project as a basis for forecasting, which is translated into regression. The tender process in Indonesia is sometimes influenced by local culture. Relations based on trust between customers (owner) and contractors can reduce project estimation calculations in detail. The contractor is sufficient to only identify and roughly describe the project requirements and carry out price negotiations.

Cost significant items can be collected by using a variety of techniques into the same number of significant items of work that can present the right proportion of the total budget cost which is usually close to $80 \%$. The total value of the project can usually be calculated by multiplying the total price of the significant packages with the right factor, which is close to 1.25 . The value of this factor varies depending on the category and analysis of historical data. The work package is planned to reflect the implementation of the field, thus feedback and control can be facilitated. The similarity is only about $10 \%$ of the total items from the conventional budget[5].

Simplification of this model reduces the time to estimate costs compared to traditional budget, which can consist of thousands of items. Cost Significant Models can be used to estimate costs better than $5 \%$, and the final calculation is better than $1 \%$. Its accuracy can be increased or reduced by improving the model and depending on the data. 
According to Poh and Horner [5], the Cost Significant Model method is carried out through the following stages:

1. Do not include work items that are sometimes quite large but not every job. These items are often high-cost variables and depend heavily on the characteristics of the field and customer requirements, which will hinder the accuracy of the development of the model.

2. Grouping work items where merging work items can be carried out if the work has the same unit of measurement, the price of the unit is not significantly different or can describe the operation of fieldwork

3. Calculate the effect of time value on the prices of work items. The price of the work in the implementation year is adjusted to the price of the projected year taking into account the inflation factor.

4. Look for cost-significant items, which are identified as the biggest items whose percentage amounts are equal to or greater than $80 \%$ of the total project costs.

5. Make a cost model of predetermined cost significant items.

6. Look for the Average Cost Model Factor (CMF). CMF is obtained by dividing the project value obtained from the model with the actual value of the project.

7. Calculate project cost estimates from the Cost Significant Model, by dividing the project value predicted from the model with the CMF average.

8. Calculate the accuracy of the model in the form of a percentage of the difference between the predicted price and the actual price divided by the actual price.

\subsection{Analysis of Multiple Linear Regression}

Before analyzing the data to test the proposed research hypothesis, the classic assumption test is done first. This is done to find out, test, and ensure the feasibility of the regression model carried out in this study. In addition, the classic assumption test is conducted to determine whether the research sample has met the classical assumption test, namely:

a. Normality test

b. Non Multicollinearity Test

c. Non-Heteroscedasticity Test

Multiple regression equation is a regression equation using two or more independent variables. The general form of the regression equation in this study are:

$\mathrm{Y}=\mathrm{a}+\beta_{1} \mathrm{X}_{1}+\beta_{2} \mathrm{X}_{2}+\beta_{3} \mathrm{X}_{3}+\ldots . .+\beta_{\mathrm{p}} \mathrm{X}_{\mathrm{p}}+\mathrm{e}_{1}$

Where:

Y = dependent variable

a constants

$\beta_{\mathrm{i}} \quad$ = regression coefficient

$\mathrm{X}_{\mathrm{i}} \quad$ = independent variable

e $\quad=$ error

From this equation, we will predict the value of $\mathrm{Y}$ if the value of the independent variable $(\mathrm{X})$ is known. Multiple regression analysis in addition to measuring the strength of the relationship between two or more variables also shows the direction of the relationship between the independent variable and the dependent variable.

If the $\beta$ coefficient is positive $(+)$, then there is a direct influence between the independent variable and the dependent variable, and vice versa, if the $\beta$ coefficient is (-) then this indicates a negative influence where the increase in the value of the independent variable will result in a decrease in the dependent variable.

a. Correlation Coefficient Test (R) 
The simple symbolized correlation coefficient $(r)$ is a measure of the direction and strength of a linear relationship between two independent variables $(\mathrm{X})$ and a dependent variable $(\mathrm{Y})$, with the provision that $r$ values range from price $(-1 \leq r \leq+1)$. If the value of $r=-1$ means that the correlation is perfectly negative (stating the direction of the relationship between $\mathrm{X}$ and $\mathrm{Y}$ is negative and very strong), $\mathrm{r}=0$ means that there is no correlation, $\mathrm{r}=1$ means the correlation is very strong in a positive direction.

b. The coefficient of determination test (R2)

The coefficient of determination test (R2) is used to describe how far the ability of the model in explaining variations in the dependent variable [6]. The higher the value of the coefficient of determination means the greater the influence of the independent variable on the dependent variable. The coefficient of determination is between 0 and one. The small value of R2 means that the ability of independent variables to explain the dependent variable is very limited, while the value of $\mathrm{R} 2$ that approaches one means that the independent variables almost all the information needed to predict variations in the dependent variable.

c. F test statistic

The F statistical test shows that overall the independent variables in the research model significantly influence the dependent variable. This test aims to test whether all the independent variables included in the model have a joint influence on the independent variables. To predict the accuracy or compatibility of the regression model used in this study can be done using the $\mathrm{F}$ test with the model match test procedure rejected if $\alpha>0.05$, and the model match test is accepted if $\alpha<0.05$

d. t-test statistic

The $\mathrm{t}$ statistical test is used to test the hypothesis. The t-test statistic is basically used to show how far the influence of an independent variable individually in explaining the dependent variable variance [6]. to see the effect of each independent variable partially on the dependent variable with the procedure if the significance level is 50.05 then Ho is rejected and $\mathrm{Hi}$ is accepted, meaning that there is an influence between the independent variable and the dependent variable. Conversely, if a significant level> 0.05 then Ho is accepted and Hi is rejected, meaning there is no influence between the independent variable and the dependent variable.

\section{Method}

\subsection{Research Design}

This research is included in research with descriptive analysis and inferential analysis approaches. Descriptive statistical analysis is useful for getting descriptive information about research variables.

Descriptive statistics are intended to analyze collected data as they are without intending to make a conclusion that applies to the public. So this type of analysis is supporting further data analysis. While inferential analysis is done by multiple regression analysis which is used to determine the model of estimated project costs. This multiple regression analysis uses construction costs as the dependent variable and the cost of work items as independent variables.

\subsection{Object Research}

This study took the object of research at the Office of Public Works and Spatial Planning of Sidoarjo Regency, for the construction of rehabilitation and improvement of channels in Sidoarjo. 


\subsection{Research Data}

The research data was taken by carrying out a census on the cost budget plan (RAB) packages for rehabilitation and channel improvement work in Sidoarjo Regency that was similar, funds sourced from the Regional Budget (APBD) from 2014-2016. The research data consisted of almost the same project data as 101 work packages.

\subsection{Location and Time of Research}

This research took place in Sidoarjo Regency, with the object of research being the Office of Public Works and Spatial Planning of Sidoarjo Regency for activities in the construction of rehabilitation and improvement in the Sidoarjo Regency.

\subsection{Data Collection Procedure}

In this study, data collection was carried out by direct observation method with the following references:

1. Collect similar project history data.

2. Data collected is work packages for the last 3 years budget.

3. Data compiled in the form of a Budget Plan (RAB), which is made by the Operations and Water Maintenance Division of the Public Works Agency and Sidoarjo Regency Spatial Planning for each work package.

4. Price of components of work costs and total work costs collected without Value Added Tax (VAT).

\subsection{Data Analysis Technique}

The data analysis technique used in this study is to use multiple regression analysis where the dependent variable is the project cost, while the independent variable is the work items involved in the project. The regression model in this study can be written as follows:

$\mathrm{Y}=\mathrm{a}+\mathrm{b}_{1} \mathrm{X}_{1}+\mathrm{b}_{2} \mathrm{X}_{2}+\mathrm{b}_{3} \mathrm{X}_{3}+\ldots \ldots \mathrm{e}_{1}$

Where,

$\mathrm{Y}=$ Total channel construction costs

$\mathrm{a}=$ Constants

$\mathrm{b}_{\mathrm{i}}=$ Regression coefficient

$\mathrm{X}_{\mathrm{i}}=$ Project items

$\mathrm{e}_{\mathrm{i}}=$ Residual or error

Before analyzing the data, data is initially grouped based on project items. Furthermore, the data analysis techniques in this study are carried out in the following stages:

(1) Calculation of the effect of time value;

(2) Determine cost-significant items;

(3) Test requirements for analysis;

(4) Analysis of data; and

(5) Testing the model. 


\section{Result and Discussion}

\subsection{Project Data}

Similar project history data is obtained from the RAB (Cost Budget Plan) on channel construction projects in the Public Works and Spatial Planning Office of Sidoarjo Regency. The data collected amounts to 101 work packages from 2014 to 2016. The price in question does not include Value Added Tax (VAT).

Data presented includes year of implementation, location, channel length, total project cost (Y) and grouping of work cost components. The data has gone through the calculation process on each item, based on the analysis of the work unit for each work package. The grouping of work cost components is adjusted to the identification of predetermined independent variables including preliminary work, earthworks, pair work, and concrete work.

\subsection{Data Processing}

The principle used to obtain the cost model formula is to use multiple linear regression. Before the data is entered into the statistical program, secondary data processing is needed. The channel length for each channel construction work package is different. For data uniformity, the existing data is adjusted to be the cost per $m$ channel length. The total work cost and work cost component are divided by the channel length for each work package, so $\mathrm{Y}$ is the cost per $\mathrm{m}$ channel length and $\mathrm{Xi}$ is the cost component per m channel length.

The implementation of this channel development project is a 2014 to 2016 budget year project, so for uniformity with other projects which are also taken as input data, each price must be brought to the price in the specified year, in this case projected to 2017. As a result the price must be adjusted to the inflation prevailing in that year.

The inflation data used is general inflation obtained from the Central Statistics Agency (BPS).

Table 1. General Inflation in Sidoarjo

\begin{tabular}{cc}
\hline Year & Inflation \\
\hline 2014 & $8.36 \%$ \\
\hline 2015 & $3.35 \%$ \\
\hline 2016 & $3.02 \%$ \\
\hline
\end{tabular}

Source : BPS

For example, the channel construction project in Tambak Rejo Village, Waru District in 2014 , is projected in 2017 :

Total cost $/ \mathrm{m}=$ Rp. $7 \cdot 125 \cdot 013,12(1+0,0836)^{1}(1+0,0335)^{1}(1+0,0302)^{1}=$ Rp. $8 \cdot 220 \cdot 281,53$

\subsection{Description of Research Data}

Descriptive analysis is used to describe data in a quantitative form without including decision making. Data is presented in descriptive form without being processed with other analytical techniques. Furthermore, the cost-significant items were identified as the largest items with the same percentage or greater than $80 \%$ of the total cost. The independent variable identified as cost-significant items is used in the subsequent analysis.

The calculation results show the percentage of each component of the work as well as the ranking starting from the component of work that has the largest cost up to the cost component with the smallest percentage of costs. It is known, there are five components of the cost that the 
percentage costs more than $80 \%$, indicating there are 5 items of work that have a percentage equal to or more than $80 \%$, with the order of starting work items that require the largest cost to the smallest, namely:

1. Stone Masonry

2. Plastering

3. Concrete work

4. Reinforcement

5. Pile work

Table 2. Cost Significant Item

\begin{tabular}{lcc}
\hline Work Component & Cost Total & Percent \\
\hline Stone Masonry & 90.764 .782 & $41.17 \%$ \\
\hline Plestering & 14.115 .069 & $6.40 \%$ \\
\hline Concrete work & 29.149 .528 & $13.22 \%$ \\
\hline Reinforcement & 27.014 .081 & $12.25 \%$ \\
\hline Pile work & 20.924 .796 & $9.49 \%$ \\
\hline Total Cost & $\mathbf{1 8 1 . 9 6 8 . 2 5 6}$ & $\mathbf{8 2 . 5 4 \%}$ \\
\hline \multicolumn{2}{c}{ Source: Data Analysis }
\end{tabular}

Thus, in the subsequent analysis the total cost (Y) is used as the dependent variable, and the independent variable consists of pairs of stone times (X1), broadcasts (X2), concrete (X3), reinforced iron (X4), and piles (X5).

\subsection{Determine the Cost Significant Item}

The five cost components in the previous sub-chapter are known as the cost significant item, then the items are calculated as future projections for 2017 costs. After that, determining the cost-significant items will be analyzed using the SPSS program, using the Stepwise Method that is a method for determining the dominant independent variable. Variables that have been included in the regression model can be removed from the model. This method starts by entering the independent variable which has the strongest correlation with the dependent variable. Then every time you enter another independent variable, a test is carried out to keep entering the independent variable or issuing it.

\subsection{Testing of Regression Assumptions}

\subsubsection{Normality test}

Normality testing in this study uses the Kolmogorov-Smirnov statistic, carried out by comparison guidelines if the significance value is greater than the 5\% significance level so it is concluded that the data is normally distributed [6]. The Kolmogorov-Smirnov test results show a Z-count value of 2.107 and a significance value of 0.000 , this significance value is smaller than $5 \%$ so it is concluded that the data is not normal.

To normalize data can be done by removing outliers, or extreme observations. Outlier results indicate that the number of outliers is known to be 3 , so the amount of data used for the model of the estimated cost of construction of the remaining channels is $98(101-3=98)$. 
The results of the normality test after removing the outliers with the Kolmogorov-Smirnov test show that the Z-count is 1.030 and the significance value is 0.239 , this significance value is greater than $5 \%$ so that the data are normally distributed.

\subsubsection{Multicollinearity Test}

Multicollinearity testing in this study uses VIF statistics, carried out by comparison guidelines if the VIF value is smaller than 10, it is concluded that there is no multicollinearity in the regression model [6], or it can be said that assumptions are fulfilled. The regression results after eliminating outliers show the VIF value on all independent variables (work items), the values are all less than 10 , so it can be concluded that there is no multicollinearity and assumptions fulfilled.

\subsubsection{Heteroscedasticity Test}

Heteroscedasticity testing in this study uses the glejser test, carried out with a comparison guide if the significance value on all independent variables is greater than the 5\% significance level, concluding that there is no heteroscedasticity, or assumptions fulfilled [6]. The glejser test results show a significant value on all independent variables (work items), the values are all more than 5\%, so it can be concluded that heteroscedasticity does not occur in the regression model, or in other words the assumptions are fulfilled.

\subsection{Estimated Cost Significant Model using Regression}

\subsubsection{Regression Equation}

The result of stepwise regression shows that there is one independent variable which is included in the exclude variables category, namely broadcast so that the variable is known to have no significant effect on the total cost of building the channel per m. Furthermore, the cost model only uses concrete variables, river stone pairs, reinforcement, and piles. The results of the regression coefficient calculation show the regression coefficients of each cost component, namely:

Table 3: Regression Coeficient

\begin{tabular}{cc}
\hline Independent Variable & Coeficient \\
\hline Intercept & $71.864,499$ \\
\hline Stone Masonry $(\mathrm{Rp} / \mathrm{m})$ & 1,257 \\
\hline Concrete $(\mathrm{Rp} / \mathrm{m})$ & 1,235 \\
\hline Reinforcement $(\mathrm{Rp} / \mathrm{m})$ & 0,990 \\
\hline Pile work $(\mathrm{Rp} / \mathrm{m})$ & 1,605 \\
\hline
\end{tabular}

Source: Data Analysis

$\mathrm{Y}=71.864,499+1,257 \mathrm{X}_{1}+1,235 \mathrm{X}_{3}+0,990 \mathrm{X}_{4}+1,605 \mathrm{X}_{5}$

$\mathrm{X}_{1} \quad$ : Stonemasonry

$\mathrm{X}_{3} \quad$ : Concrete work

$\mathrm{X}_{4} \quad$ : Reinforcement

$\mathrm{X}_{5} \quad$ : Pile work

$\mathrm{Y} \quad$ : Estimated Total Work Costs

The regression coefficient explains two things, first about the magnitude of the influence and second about the direction of influence. The greater the regression coefficient, the greater the effect, and conversely the smaller the regression coefficient, the smaller the effect. As for 
the direction of influence, it is known that all regression coefficients have a positive sign, so that it has a direction that is in the same direction (not reversed), meaning that the cost of stone pairs, reinforcement costs, and cost of piling, will increase the total cost channel construction.

\subsubsection{Coefficient of Determination}

The calculation of the determination coefficient (R-square) is 0.979 , meaning that the percentage of the influence of the land excavation work items, stone masonry work, concrete work, reinforcement, and pile work on the total cost of building the channel is $97.9 \%$, while the remaining $2.1 \%$ is influenced by other factors.

\subsubsection{F-Statistics Test}

The $\mathrm{F}$ test is used to determine the simultaneous effect of independent variables on the dependent variable, and can also be used to find out whether the model or regression equation is fit (fit) or not, if the F test produces a significance value smaller than the 5\% significance level, then the fit regression equation is concluded. corresponding. The results of the F test show that the calculated $\mathrm{F}$ value is 1087,357 and the significance value is 0,000 (smaller than 5\%), so it is concluded that the equation or model of the estimated cost of constructing the channel has been fit, so that it is suitable for predictions.

\subsubsection{Statistic t-test}

The t-test is used to determine the effect of partial independent variables on the dependent variable if the t-test produces a significance value smaller than the $5 \%$ significance level, it is concluded that there is a significant effect of the independent variable on the dependent variable. The results of the t-test show that the cost of the stone pair work has a tcount of 30,527 and a significance value of 0,000 because the significance value (sig.) Is less than $5 \%$, it is concluded that the stone pairing has a significant effect on the total cost of building the channel.

The t-test results also show the cost of concrete work has a t-count of 9,681 and a significance value of 0,000 because the significance value (sig.) Is smaller than $5 \%$, it is concluded that concrete work also has a significant effect on the total cost of building the channel.

Table 4: Result of $t$ test

\begin{tabular}{ccc}
\hline Independent Variable & t-Calculate & Sig \\
\hline Intercept & 1,694 & 0,094 \\
\hline Stone Masonry & 30,527 & 0,000 \\
\hline Concrete & 9,681 & 0,000 \\
\hline Reinforcement & 17,523 & 0,000 \\
\hline Pile Work & 15,779 & 0,000 \\
\hline
\end{tabular}

Source: Data Analysis

The t-test results also show the cost of reinforcing ironwork has a t-count of 17,523 and a significance value of 0,000 because the significance value (sig.) Is smaller than $5 \%$, it is concluded that reinforcing iron work also has a significant effect on the total cost of channel construction. 
The results of the t-test also show the cost of the pile work has a t-count of 15,779 and a significance value of 0,000 because the significance value (sig.) Is smaller than $5 \%$, it is concluded that the pile work also has a significant effect on the total cost of building the duct.

\subsubsection{Correlation Test}

Correlation test is used to determine the level of relationship between the independent variable and the dependent variable. Correlation test results are presented showing that the work of the stone masonry, concrete, reinforcement, and pile has a strong correlation value with a significance value of all smaller than $5 \%$, so it is concluded that the four components of the work are significantly related to the total cost of building the channel.

Table 5: Result of Correlation Test

\begin{tabular}{|c|c|c|}
\hline $\begin{array}{c}\text { Correlation Variable with } \\
\text { Total Cost }\end{array}$ & $\begin{array}{c}\text { Correlation } \\
\text { Value }\end{array}$ & Sig \\
\hline Stone Masonry & 0,784 & 0,000 \\
\hline Concrete & 0,717 & 0,000 \\
\hline Reinforcement & 0,654 & 0,000 \\
\hline Pile Work & 0,754 & 0,000 \\
\hline
\end{tabular}

Source: Data Analysis

\subsection{Model Testing}

In this study the estimated cost of the model is calculated by entering the unit price of work per $\mathrm{m}$, into the regression equation that has been produced previously. The results of cost estimation with the Cost Significant Model are obtained by dividing the estimation model with Cost Model Factor (CMF). CMF is the average ratio of the estimated cost of the model to the actual cost.

The estimated cost significant model results are obtained from the calculation compared to the implementation costs (actual costs) of the project reviewed. It is known that the average CMF value is 1.00000 , which shows the prediction of the total cost of building a channel using a very good cost-significant model, or it is in accordance with the cost of building a real channel according to the RAB.

The level of accuracy is to calculate the difference from the estimated cost significant model with implementation costs, divided by the cost of implementation, and multiplied by $100 \%$. In comparison, the accuracy of the method used so far is calculated, namely the channel length parameter method for the implementation cost.

The magnitude of the accuracy of the model, the positive value of bili states that the estimated cost is greater than the implementation cost (actual costs), whereas the opposite if the accuracy of the model is negative states that the estimated cost is smaller than the implementation cost (actual cost). Accuracy with "Cost Significant Model "Ranges from -18.7\% to $+10.5 \%$, with an average of $+0.2 \%$. Thus, the estimated cost with the "Cost Significant Model" developed produces a very good estimate.

In this study, the channels that become the research data are short and medium, namely with a channel length range between $18 \mathrm{~m}$ to $139 \mathrm{~m}$. In the construction of the channel in length, the prediction of the model becomes very precise, while in the construction of the channel with a long channel, further research is needed so that the prediction of the model becomes precision, this is because the longer the channel the lower the cost per meter. 


\section{Conclusion}

Based on the results of the research that has been carried out, conclusions can be obtained as follows:

1. The work item that has the most significant influence on the cost of constructing the channel work is the item of the Batu Kali Couple work with the highest beta coefficient $=0.505$ and the highest correlation coefficient $=0.787$. While the influence of the size of the work items of Couples Stone, Concrete, Pile and Reinforcement Iron on the total cost of the work channel is $97.9 \%$, while the remaining $2.1 \%$ is influenced by other causes.

2. The model of estimating the cost of channel work with the "Cost Significant Model" is: $\mathrm{Y}=71.864,499+1,257 \mathrm{X}_{1}+1,235 \mathrm{X}_{3}+0,990 \mathrm{X}_{4}+1,605 \mathrm{X}_{5}$

\section{Where :}

$\mathrm{X}_{1}$ : Stone masonry

$\mathrm{X}_{3}$ : Concrete work

$\mathrm{X}_{4}$ : Reinforcement

$\mathrm{X}_{5}$ : Pile work

Accuracy of the estimated cost model of the channel work with the "Cost Significant Model" method varies between $-18.7 .0 \%$ to $10.5 \%$, with an average accuracy rate of $0.2 \%$. Comparison of average cost per $m$ of estimated cost the significant model is Rp.2,300,809,009, with actual costs of Rp.2,300,809,008; with the difference between CSM and the actual cost of HPS almost zero; $(\mathrm{CMF}=1.00000 \%)$ and the average accuracy rate of $0.2 \%$.

\section{Recommendations}

Based on the conclusions of the study as described earlier, the following matters can be suggested:

1. Noting the results of the accuracy of the model obtained, the estimated cost with the "Cost Significant Model" can be considered for use in the early stages of the channeling project development planning budget within the Public Works and Spatial Planning Office of Sidoarjo Regency.

2. For further research, it is necessary to use another method to produce a model for estimating the cost of building a channel in addition to the cost significant model, namely using the building cost index method. Mulyono (2015) explains, the building cost index method is a number that shows the ratio of cost per $\mathrm{m} 2$ cost component at a certain time period, the cost index is obtained from the analysis of similar work unit prices taking into account the dominant work component and project implementation time.

Further research is needed for the channel work that is more than 200 meters long.

\section{References}

[1] B. Mulyono and A. Apriyono, "Model Estimasi Biaya Konsetua Bangunan Jembatan Beton Prategang (Studi Kasus Di Provinsi Jawa Tengah dan D.I.Y)," in Prosiding Konferensi Nasional Teknik Sipil 9 (KoNTekS 9), 2015.

[2] A. Husen, Manajemen Proyek Perencanaan, Penjadwalan \& Pengendalian Proyek. Yogyakarta: Andi Offset, 2009.

[3] I. Soeharto, Manajemen Proyek Dari Konseptual Sampai Operasional. Jakarta: Erlangga, 1997.

[4] A. Hájek and N. Hall, "The hypothesis of the conditional construal of conditional 
probability," in Probability and Conditionals: Belief Revision and Rational Decision, E. Eells, B. Skyrms, and E. W. Adams, Eds. Cambridge University Press, 1994.

[5] P. Paul and R. Malcolm, W. HORNER, "Cost-significant modelling - its potential for use in south-east Asia," Eng. Constr. Archit. Manag., vol. 2, no. 2, pp. 121-139, Jan. 1995.

[6] I. Ghozali, Aplikasi Analisis Multivariate Dengan Program SPSS. Semarang: BP. UNDIP, 2013. 